independent predictor of relapse risk, highlighting the need for a correct characterization of the clinical subtype at the early stages of disease.

Disclosure of Interests: Sara Monti: None declared, Lorenzo Dagna Grant research support from: Abbvie, BMS, Celgene, Janssen, MSD, Mundipharma Pharmaceuticals, Novartis, Pfizer, Roche, SG, SOBI, Consultant of: Abbvie, Amgen, Biogen, BMS, Celltrion, Novartis, Pfizer, Roche, SG, and SOBI, Corrado Campochiaro Speakers bureau: Novartis, Pfizer, Roche, GSK, SOBI, Alessandro Tomelleri: None declared, Giovanni Zanframundo: None declared, Catherine Klersy: None declared, Francesco Muratore: None declared, Luigi Boiardi: None declared, Roberto Padoan: None declared, Mara Felicetti: None declared, Franco Schiavon: None declared, Milena Bond: None declared, Alvise Berti: None declared, Roberto Bortolotti: None declared, Carlotta Nannini: None declared, Fabrizio Cantini: None declared, Alessandro Giollo: None declared, Edoardo Conticini: None declared, angelica gattamelata: None declared, Roberta Priori: None declared, Luca Quartuccio Consultant of: Abbvie, Bristol, Speakers bureau: Abbvie, Pfizer, Elena Treppo: None declared, Giacomo Emmi: None declared, Martina Finocchi: None declared, Giulia Cassone: None declared, Ariela Hoxha Speakers bureau: Celgene, UCB, Novartis, Sanofi, Werfen, Rosario Foti Consultant of: lilly, sanofi, MSD, Janssen, Abbvie, BMS, celgene, roche, Speakers bureau: lilly, sanofi, MSD, Janssen, Abbvie, BMS, celgene, roche, Michele Colaci: None declared, Roberto Caporali Consultant of: AbbVie; Gilead Sciences, Inc.; Lilly; Merck Sharp \& Dohme; Celgene; Bristol-Myers Squibb; Pfizer; UCB, Speakers bureau: Abbvie Bristol-Myers Squibb; Celgene; Lilly; Gilead Sciences, Inc; MSD; Pfizer; Roche; UCB, Carlo Salvarani: None declared, Carlomaurizio Montecucco: None declared DOI: 10.1136/annrheumdis-2020-eular.3779

\section{FRI0213 \\ ASSOCIATION BETWEEN SPECIMEN LENGTH AND NUMBER OF SECTIONS AND DIAGNOSTIC YIELD OF TEMPORAL ARTERY BIOPSY: A RETROSPECTIVE, SINGLE CENTER EXPERIENCE OVER A 21 YEARS' PERIOD}

F. Muratore $^{1}$, L. Boiardi ${ }^{1}$, A. Cavazza ${ }^{2}$, T. Giacomo ${ }^{3}$, R. Aldigeri ${ }^{4}$, L. Cimino ${ }^{5}$, C. Salvarani $6 .{ }^{1}$ Division of Rheumatology, Azienda Unita' Sanitaria Locale IRCCS di Reggio Emilia, Reggio Emilia, Italy; ${ }^{2}$ Pathology Unit, Azienda Unita' Sanitaria Locale IRCCS di Reggio Emilia, Reggio Emilia, Italy; ${ }^{3}$ Division of Rheumatology, University of Modena and Reggio Emilia, Modena, Italy; ${ }^{4}$ Department of Medicine and Surgery, University of Parma, Parma, Italy, Parma, Italy; ${ }^{5}$ Ophthalmology Unit, Azienda Unita' Sanitaria Locale IRCCS di Reggio Emilia, Reggio Emilia, Italy; ${ }^{6}$ Division of Rheumatology, Azienda Unita' Sanitaria Locale IRCCS di Reggio Emilia and University of Modena and Reggio Emilia, Reggio Emilia, Italy

Background: Temporal artery biopsy (TAB) showing inflammation is considered the gold standard for the diagnosis of giant cell arteritis (GCA). However, sampling error may lead to a negative $T A B$, and a negative $T A B$ does not rule out GCA. The diagnostic sensitivity of TAB can be affected by the discontinuous character of the histopathologic changes (skip lesions) and by the length of specimens. The optimal TAB length and the optimal number of sections that need to be evaluated in order to avoid missing skip lesions are controversial.

Objectives: To investigate the association between specimen length and number of section and the diagnostic yield of TAB for GCA.

Methods: A pathologist with expertise in vasculitis and blinded to clinical data and final diagnosis reviewed all TABs performed for suspected GCA at our hospital between January 1991 and December 2012. The biopsies were routinely fixed in formalin and completely embedded in paraffin. Sections of 4 microns thickness were cut from paraffin blocks and stained with hematoxylin-eosin. TABs were classified into three categories: inadequate, when the biopsy did not sample the muscular artery; negative when the temporal artery was devoid of inflammation and positive when the temporal artery showed inflammation, arbitrarily defined as at least 1 aggregate of at least 15 inflammatory cells. The blocks of all the inadequate and negative biopsies were recut, and at least three further slides at deeper levels were stained with hematoxylin-eosin

Results: 694 TABs were performed in the study period and were reviewed. 32 $(4.6 \%)$ were classified as inadequate and were excluded from the analysis. Of the remaining 662 TABs [71\% female; mean (SD) age, 73.2 (8.8) years], mean (SD) post fixation length was $6.63(4.42) \mathrm{mm}$, and median number of sections evaluated was 3 (range 1-33). 382 (58\%) TABs were classified as negative and $280(42 \%)$ as positive. Compared with negative TAB, patients with positive TAB were older [mean age (SD) $74(7.5)$ years vs $72(9.6), p=0.009$ ] and there was a trend for female predominance $(75 \%$ vs $68 \%, p=0.077)$. Post fixation length of the specimens was significantly lower in negative compared with positive TAB [mean (SD) $6.37(4.26) \mathrm{mm}$ vs 6.99 (4.61) respectively, $\mathrm{p}=0.026$ ]. Piecewise logistic regression identified $5 \mathrm{~mm}$ as the TAB length change point for diagnostic sensitivity. Compared with TAB length of $<5 \mathrm{~mm}$, age- and sex-adjusted odds ratio for positive $\mathrm{TAB}$ in samples $\geq 5 \mathrm{~mm}$ long were 1.536 (95\% confidence interval, 1.108 to 2.130 )
The median (IQR) number of sections evaluated were 2 (1-3) for positive TAB and 4 (2-5) for negative TAB, p<0.0001. In 26/280 (9.3\%) positive TABs, the first section was negative, and the inflammation was detected only in deeper sections (the positive section was the second in 14 TABs, the third in 9 and the fourth in 3 ). In all 26 cases, inflammation detected in deeper section was not transmural, but limited to adventitial or periadventitial small vessels.

Conclusion: Our data confirm that a post fixation TAB length of at least $5 \mathrm{~mm}$ should be sufficient to make a histological diagnosis of inflamed temporal artery. According to our data, in order to avoid missing skip inflammatory lesions, at least 3 further sections at deeper levels should be cut and evaluated in all negative TABs.

Disclosure of Interests: None declared

DOI: 10.1136/annrheumdis-2020-eular.5485

\begin{tabular}{|l|l|}
\hline FRI0214 & PERSISTENT LOW-GRADE FDG-PET VASCULAR \\
INFLAMMATION IN REMITTED LVV-GCA PATIENTS \\
IS ASSOCIATED TO A SIGNIFICANT HIGH RISK OF \\
RELAPSE
\end{tabular}

R. Padoan ${ }^{1}$, A. Tomelleri ${ }^{2}$, M. Felicetti ${ }^{1}$, C. Campochiaro ${ }^{2}$, E. Baldissera ${ }^{2}$, F. Crimi ${ }^{3}$, P. Zucchetta ${ }^{4}$, D. Cecchin ${ }^{4}$, M. Picchio ${ }^{5}$, L. Dagna ${ }^{2}$, A. Doria ${ }^{1}$, F. Schiavon ${ }^{1} .{ }^{1}$ Rheumatology Unit, University of Padova, Padova, Italy; ${ }^{2}$ Unit of Immunology, Rheumatology, Allergy and Rare Diseases, IRCCS San Raffaele Hospital, Milano, Italy; ${ }^{3}$ Radiology Unit, University of Padova, Padova, Italy; ${ }^{4}$ Unit of Nuclear Medicine, University of Padova, Padova, Italy; ${ }^{5}$ Unit of Nuclear Medicine, IRCCS San Raffaele Hospital, Milano, Italy

Background: Persistent low-grade vascular inflammation in giant cell arteritis (GCA) with large vessel involvement (LVV) treated patients could represent the expression of persistent subclinical disease activity or post-inflammatory vascular remodelling. Whether these findings have any impact on future vascular outcomes is still an unmet need.

Objectives: To evaluate the frequency and evolution of FDG-PET low-grade vascular inflammation in remitted LVV-GCA patients.

Methods: We included all consecutive patients classified as GCA with LVV involvement, with a minimum disease duration of 12 months and clinically remitted, who underwent to at least one PET/MR scan between January 2015 and January 2020 For each scan vessel's metabolic activity was assessed using the Meller's grading ${ }^{1}$. Low-grade inflammation was defined as Meller 1 and 2 (inferior or equal to liver) as reported in previous studies. Demographic and clinical data, as well as disease remission or flares, were recorded and compared to vascular metabolic activity.

Results: In total 88 PET scans were performed in 54 LVV-GCA patients, predominantly female $(77.8 \%)$, aged $68[7,8]$ years, with a regular BMI $(23.9[2.8])$ and with a long-standing disease (27[32.6] months). A subsequent PET/MR scan was available in 34 patients (median time between the two scans $9[6.3$ months).

At first PET examination, low-grade metabolic activity was reported in $68,5 \%$ of the cases, while complete remission in $15 \%$ and high metabolic activity in $25 \%$. Comparing patients with low-grade vascular inflammation to those with complete remission (Meller 0), they had lower disease duration (28[25.9] vs 73[68] months, but without significance) and they were treated with higher daily prednisone dosage (5[3.8] vs 0 [2.2], $\mathrm{p}=0.042)$. No significant differences were noted in age, acute phase reactants and type of treatment. Moreover, when compared to those with high metabolic activity (Meller 3 ), the latter had only significantly higher CRP levels (8.3[13.8] vs 4.1[3.9], $p=0.03$ ) and lower disease duration (19[20.6] vs 28[25.9] months, but without significance). While no significant differences were noted in age and type of treatment (both glucocorticoids and immunosuppressants)

Among all patients with low-grade vascular inflammation, $81 \%$ of them under went to steroids or immunosuppressants tapering due to clinical remission. A the subsequent PET examination, a worsening of metabolic activity (Meller 3 ) was found in $4 / 20$ patients, with 1 clinical flare. While in 14/20 patients the subsequent PET revealed a persistent metabolic activity. Only in 2/20 there was a complete metabolic remission. Change or increase of the treatment regimen led to an improvement (Meller 0 or 1 ) in all the cases. Low-grade metabolic activity was associated with a significant increased risk of worsening/flare at the subsequent PET examination (RR 5.29[1.87-16.11], $p=0.002$ )

Conclusion: Low-grade vascular inflammation at PET examination is a common feature in remitted patients. It is associated with older age, lower disease duration and clinical remission. Treatment tapering is associated with an increased risk of worsening/flare. Further research is urgently needed to address this issue.

References:

[1] J. Meller et al., "Early diagnosis and follow-up of aortitis with [(18)F]FDG PET and MRI.," Eur. J. Nucl. Med. Mol. Imaging, vol. 30, no. 5, pp. 730-6, May 2003.

Disclosure of Interests: Roberto Padoan: None declared, Alessandro Tomelleri: None declared, Mara Felicetti: None declared, Corrado Campochiaro 
Speakers bureau: Novartis, Pfizer, Roche, GSK, SOBI, Elena Baldissera Speakers bureau: Novartis, Pfizer, Roche, Alpha Sigma, Sanofi, Filippo Crimì: None declared, Pietro Zucchetta: None declared, Diego Cecchin: None declared, Maria Picchio: None declared, Lorenzo Dagna Grant/research support from: Abbvie, BMS, Celgene, Janssen, MSD, Mundipharma Pharmaceuticals, Novartis, Pfizer, Roche, SG, SOBI, Consultant of: Abbvie, Amgen, Biogen, BMS, Celltrion, Novartis, Pfizer, Roche, SG, and SOBI, Andrea Doria Consultant of: GSK, Pfizer, Abbvie, Novartis, Ely Lilly, Speakers bureau: UCB pharma, GSK, Pfizer, Janssen, Abbvie, Novartis, Ely Lilly, BMS, Franco Schiavon: None declared

DOI: 10.1136/annrheumdis-2020-eular.6478

\begin{tabular}{|l|l}
\hline FRI0215 & RESPONSE TO TOCILIZUMAB IN LARGE VESSEL \\
VASCULITIS ACCORDING TO THE EXTENT OF \\
BASELINE 18F-FDG VASCULAR UPTAKE
\end{tabular}

D. Prieto-Peña ${ }^{1}$, M. Calderón-Goercke ${ }^{1}$, I. Martínez-Rodríguez ${ }^{1}$, J. I. Banzo ${ }^{1}$, P. Vicente-Gómez ${ }^{1}$, J. García-Fernández ${ }^{1}$, M. A. González-Gay ${ }^{1}$, R. Blanco' ${ }^{1}$. ${ }^{1}$ Marqués de Valdecilla University Hospital, Santander, Spain

Background: ${ }^{18} \mathrm{~F}-\mathrm{FDG}$ PET/CT is useful to establish the presence and extent of large vessel vasculitis (LVV)(1-2). Early therapy is needed to prevent severe complications. Tocilizumab (TCZ) has shown efficacy in LVV (3-5). However, it is unknown if the extent of FDG vascular uptake may influence on clinical response to TCZ Objectives: To assess the correlation of the extent of baseline FDG vascular uptake in PET/CT scan with clinical response to TCZ in patients with LVV.

Methods: Single center study of patients with LVV treated with TCZ who were divided into 2 groups depending on the extent of vascular uptake in baseline PET/CT scan: a) 1-2 affected areas b) $\geq$ affected 3 areas. Vascular uptake was qualitatively assessed by two experienced nuclear medicine physicians in five areas (supraaortic trunks, thoracic aorta, abdominal aorta, iliac and femorotibial arteries). We assessed clinical improvement (no improvement/partial/complete), normalization of CRP $(\leq 0.5 \mathrm{mg} / \mathrm{dL})$ and/or ESR $\left(\leq 20 \mathrm{~mm} / 1^{\text {st }} \mathrm{h}\right)$ and reduction of prednisone dose ( $\mathrm{mg} /$ day).

Results: 30 patients $(24 \mathrm{w} / 6 \mathrm{~m})$; mean age $65.3 \pm 10.6 \mathrm{yrs}$. In baseline PET/CT, vascular uptake was observed in 1 or 2 areas $(n=13)$ and in $\geq 3$ areas $(n=17)$. There was a trend to higher ESR/CRP and shorter evolution of clinical symptoms before TCZ onset in patients with $\geq 3$ affected areas (TABLE 1). Clinical/ serological evolution and reduction of prednisone dose is shown in TABLE 2. No statistical differences were found. However, patients with $\geq 3$ affected areas tended to experience a slower clinical response.

TABLE 1.

\begin{tabular}{lccc}
\hline & $\begin{array}{c}\text { 1-2 vascular affected } \\
\text { areas }(\mathbf{n}=\mathbf{1 3})\end{array}$ & $\begin{array}{c}\geq 3 \text { vascular affected } \\
\text { areas }(\mathbf{n}=17)\end{array}$ & $\mathbf{P}$ \\
\hline Demographic data & & & \\
Age, mean \pm SD & $66.0 \pm 10.8$ & $64.8 \pm 10.7$ & 0.77 \\
Sex (women), $n$ (\%) & $11(84.6)$ & $13(76.5)$ & 0.67 \\
Evolution time before TCZ (months), & $26.0[3.5-34.0]$ & $5.0[1.5-10.0]$ & 0.02 \\
$\quad$ median [IQR] & & & \\
Laboratory markers & $30.0 \pm 27.3$ & $34.8 \pm 27.6$ & 0.64 \\
ESR (mm/1st $\mathrm{h})$, mean $\pm S D$ & $1.3 \pm 1.2$ & $1.8 \pm 1.7$ & 0.28 \\
CRP (mg/dL), mean \pm SD & & & \\
Previous treatment & $9.4 \pm 6.2$ & $7.9 \pm 6.9$ & 0.53 \\
Prednisone dose (mg/day), mean $\pm S D$ & $10(76.9)$ & $11(64.7)$ & 0.47 \\
TCZ therapy & $6(46.2)$ & $8(47.1)$ & 0.96 \\
Intravenous, $\mathrm{n}(\%)$ & & & \\
Combined with MTX, $\mathrm{n}(\%)$ & & &
\end{tabular}

TABLE 2.

\begin{tabular}{lccc}
\hline & $\begin{array}{c}\mathbf{1 - 2} \text { vascular } \\
\text { affected areas } \\
(\mathbf{n}=13)\end{array}$ & $\begin{array}{c}\geq 3 \text { vascular affected } \mathbf{P} \\
\text { areas }(\mathbf{n}=17)\end{array}$ & \\
\hline Complete clinical improvement, $n / N(\%)$ & & & \\
$6 \mathrm{~m}$ & $11 / 13(84.6)$ & $12 / 17(70.6)$ & 0.43 \\
$12 \mathrm{~m}$ & $12 / 13(92.3)$ & $13 / 17(76.5)$ & 0.36 \\
$18 \mathrm{~m}$ & $10 / 11(90.9)$ & $11 / 12(91.7)$ & 0.99 \\
$24 \mathrm{~m}$ & $8 / 8(100)$ & $9 / 10(90.0)$ & 0.99 \\
Normalization of ESR and/or CRP, $n / N(\%)$ & & & \\
$6 \mathrm{~m}$ & $13 / 13(100)$ & $16 / 17(94.1)$ & 0.99 \\
$12 \mathrm{~m}$ & $13 / 13(100)$ & $16 / 17(94.1)$ & 0.99 \\
$18 \mathrm{~m}$ & $11 / 11(100)$ & $11 / 12(91.7)$ & 0.99 \\
$24 \mathrm{~m}$ & $8 / 8(100)$ & $10 / 10(100)$ & 0.99 \\
Dose of Prednisone (mg/day), median [IQR] & & & \\
$6 \mathrm{~m}$ & $5.0[1.3-5.0]$ & $5.0[0.0-5.0]$ & 0.98 \\
$12 \mathrm{~m}$ & $2.5[0.0-3.8]$ & $0.0[0.0-5.0]$ & 0.97 \\
$18 \mathrm{~m}$ & $0.0[0.0-2.5]$ & $0.0[0.0-1.9]$ & 0.72 \\
$24 \mathrm{~m}$ & $0.0[0.0-2.2]$ & $0.0[0.0-2.5]$ & 0.77 \\
\hline & & & \\
\hline
\end{tabular}

Conclusion: TCZ therapy was effective in patients with LVV regardless the extent of FDG vascular uptake in baseline PET/CT scan. However, a trend to a slower clinical response was observed in patients with $\geq 3$ affected areas. References:

[1] Martínez-Rodríguez et al. (18)F-FDG PET/CT in the follow-up of large-vessel vasculitis: A study of 37 consecutive patients. Semin Arthritis Rheum.2018 Feb;47(4):530-537. doi: 10.1016/j.semarthrit.2017.08.009.

[2] Loricera et al. Non-infectious aortitis: a report of 32 cases from a single tertiary centre in a 4-year period and literature review. Clin Exp Rheumatol. 2015 Mar-Apr; 33(2 Suppl 89): S-19-31

[3] Calderón-Goercke $M$ et al. Tocilizumab in giant cell arteritis. Observational, open-label multicenter study of 134 patients in clinical practice. Semin Arthritis Rheum. 2019 Aug; 49(1):126-135. doi: 10.1016/j. semarthrit.2019.01.003

[4] González-Gay MA et al. Current and emerging diagnosis tools and therapeutics for giant cell arteritis. Expert Rev Clin Immunol. 2018 Jul;14(7):593605. doi: 10.1080/1744666X.2018.1485491.

[5] Loricera et al. Tocilizumab in patients with Takayasu arteritis: a retrospective study and literature review. Clin Exp Rheumatol. 2016 May-Jun;34(3 Suppl 97): S44-53.

Disclosure of Interests: D. Prieto-Peña: None declared, Monica CalderónGoercke: None declared, Isabel Martínez-Rodríguez: None declared, Jose Ignacio Banzo: None declared, Patricia Vicente-Gómez: None declared, Javier García-Fernández: None declared, Miguel A González-Gay Grant/research support from: Pfizer, Abbvie, MSD, Speakers bureau: Pfizer, Abbvie, MSD, Ricardo Blanco Grant/research support from: AbbVie, MSD, Roche, Consultant of: Abbvie, Eli Lilly, Pfizer, Roche, Bristol-Myers, Janssen, UCB Pharma and MSD, Speakers bureau: Abbvie, Eli Lilly, Pfizer, Roche, Bristol-Myers, Janssen, UCB Pharma. MSD

DOI: 10.1136/annrheumdis-2020-eular.1624

\section{FRI0216 STEROID SPARING EFFECT, LOWER INCIDENCE OF DISEASE RELAPSE AND DIABETES IN GIANT CELL ARTERITIS TREATED WITH IMMUNOSUPPRESSORS AB INITIO OR VERY EARLY: A MULTICENTER RETROSPECTIVE CASE-CONTROL STUDY}

L. Quartuccio ${ }^{1}$, M. Isola ${ }^{2}$, D. Bruno ${ }^{3}$, E. Treppo ${ }^{1}$, L. Gigante ${ }^{3}$, F. Angelotti ${ }^{4}$, R. Capecchi ${ }^{4}$, G. Vitiello ${ }^{5}$, E. Cavallaro ${ }^{1}$, A. Tavoni ${ }^{4}$, S. L. Bosello ${ }^{6}$, D. Cammelli ${ }^{5}$ S. De Vita ${ }^{1}$, E. Gremese ${ }^{3,6}$. ${ }^{1}$ Department of Medical Area, Rheumatology Clinic, Udine Academic Hospital "Santa Maria della Misericordia", Udine, Italy, Udine, Italy; ${ }^{2}$ Department of Medicine, Institute of Statistics, University of Udine, Udine, Italy, Udine, Italy; ${ }^{3}$ Rheumatology Unit, Catholic University of the Sacred Heart, Rome, Italy, Rome, Italy; ${ }^{4}$ Department of Internal Medicine, Clinic of Immunology, Pisa, Italy, Pisa, Italy; ${ }^{5}$ University of Florence, Florence, Italy; ${ }^{6}$ Division of Rheumatology, Fondazione Policlinico Universitario A. GemelliIRCCS, Rome, Italy, Rome, Italy

Background: Glucocorticoids (GC) are associated with serious side effects in giant cell arteritis (GCA). Immunosuppressive therapies (IT) gave conflicting results in GCA, regarding GC sparing effect. Recently, tocilizumab by blocking IL-6, has been licensed as first biologic treatment for GCA, being clinically effective and saving GC (1).

Objectives: To evaluate the usefulness of IT for GCA in: 1) minimizing the rate of GC-induced adverse events (AEs) and 2) reducing the risk of relapse.

Methods: A multicenter retrospective case-control study included 165 GCA was performed. The first group of patients (GCA-IT) included 114 patients who were treated with at least one IT given ab initio or within 3 months from the start of GC. The control group included 51 GCA who received only GC or an IT later than 3 months (GCA-steroid). The primary endpoints were the rate of GC-related side effects: infections, hospitalized infections, new onset systemic arterial hypertension, GC-induced diabetes and osteoporotic fractures.

Results: Methotrexate up to $20 \mathrm{mg} /$ week (138 patients), followed by cyclophosphamide (48 patients) and tocilizumab (27 patients) were the most frequently used IT. No difference was observed as concerns the follow-up time between the two groups [48.5 (IQR 26-72) vs 40 (IQR 24-69), $p=0,3$, rank-sum test)]. The two groups were similar as concerns sex $(p=0,13)$, while the first group $(69 \pm 8 \mathrm{yrs})$ was slightly younger than the second one $(72 \pm 7 \mathrm{yrs})(p=0,005)$. Comorbidity was similar between groups. Patients in the GCA-IT group showed a significant lower incidence of GC-induced diabetes (8/114, $7 \%$ vs $12 / 51,23,5 \% ; p=0,003$, chi-square test), while no differences were documented for rate of infections $(p=0,64)$, including hospitalized infections $(p=0,44)$, new onset systemic arterial hypertension $(p=0,68)$, or osteoporotic fractures $(p=0,32)$. Forty-four patients in the GCA-IT group (38,6\%), while 34 patients in the GCA-steroid group $(66,7 \%)$ experienced at least one relapse ( $p=0,001$, chi square test). There was no difference in terms of time to first relapse between the two groups $(p=0,53$, logrank test). GCA-IT group was exposed to lower dose of $G C$ at first $(p<0,0001$ 